\title{
Some Simple Arguments about Cost Externalization and its Relevance to the Price of Fusion Energy
}

\author{
R. Budny ${ }^{\mathrm{a}}$ \\ Princeton Plasma Physics Laboratory \\ and \\ R. Winfree \\ Dept. of Ecology and Evolutionary Biology \\ Princeton University
}

The primary goal of fusion energy research is to develop a source of energy that is less harmful to the environment than are the present sources. A concern often expressed by critics of fusion research is that fusion energy will never be economically competitive with fossil fuels, which in 1997 provided 75\% of the world's energy [1]. And in fact, studies of projected fusion electricity generation generally project fusion costs to be higher than those of conventional methods [2]. Yet it is widely agreed that the environmental costs of fossil fuel use are high. Because these costs aren't included in the market price, and furthermore because many governments subsidize fossil fuel production, fossil fuels seem less expensive than they really are [3]. Here we review some simple arguments about cost externalization which provide a useful background for discussion of energy prices.

The collectively self-destructive behavior that is the root of many environmental problems, including fossil fuel use, was termed "the tragedy of the commons" by the biologist G. Hardin [4; see Ref. 5 for the origins of the idea, and Ref. 6 for a formal economic description]. Hardin's metaphor is that of a grazing commons that is open to all. Each herdsman, in deciding whether to add a cow to his herd, compares the benefit of doing so, which accrues to him alone, to the cost, which is shared by all the herdsmen using the commons, and therefore adds his cow. In this way individually rational behavior leads to the collective destruction of the shared resource. As Hardin pointed out, pollution is one kind of tragedy of the commons. $\mathrm{CO}_{2}$ emissions and global warming are in this sense classic tragedies.

Hardin saw two kinds of solutions to tragedies of the commons. The first is to privatize the resource - to fence the commons. This is difficult to do in the case of atmospheric pollution, though perhaps not impossible, as discussed below. The second is government regulation: legislate how many cows are allowed to graze. This has been the dominant approach to pollution to date, but in the case of $\mathrm{CO}_{2}$ emissions it makes the dubious assumption that governments can, for instance, control how much their citizens drive. It is interesting to note that in contrast to many environmentalists, neither economists nor evolutionary biologists consider appeals to conscience to be a viable solution to commons problems. Economists generally expect individuals to act in their rational self-interest, and 
the fundamental law of biology, evolution by natural selection, eliminates self-sacrificing behavior $[4,7,8]$. Yet as one review put it, "there are all sorts of ways to make the individual interest concordant with the collective — so long as we recognize the need to"'[7].

This brings us to the third type of solution: change the price of the item in to incorporate the true cost of its use. When this is done by making the polluter pay for the right to pollute - for example, the tradable sulfur dioxide emissions permits established by the United States Clean Air Act of 1990 - it is a form of privatization [7]. In effect what is privatized is a piece of the atmosphere and the right to pollute that piece, up to a prescribed limit. A new, higher price could also be established by taxation, as first suggested in the 1920s by the economist A.C. Pigou [9]. In either case, re-pricing solves the problem of cost externalization - which is just the tragedy of the commons in economic terms - by using the market.

A schematic of the relationship between price, demand, and supply is shown in Fig.1. (The lines in Fig. 1 represent a generic case, and are intended only to illustrate the qualitative effect of subsidies and cost externalization; further discussion of the shape of supply and demand curves can be found in Refs. 10 and 11.) The price consumers are willing to pay for a commodity decreases as the quantity increases, because the marginal benefit of having one more unit decreases with the quantity already available. The price suppliers charge for the same commodity tends to increase with the quantity produced, because the marginal cost of producing one more unit rises as the resource becomes scarce. The intersection of the supply and demand curves represents the equilibrium price and quantity towards which the market tends. If the market is too far to the right, supply exceeds demand and the price drops, returning the market to the equilibrium; an analogous phenomenon raises the price if the market is to the left of the equilibrium.

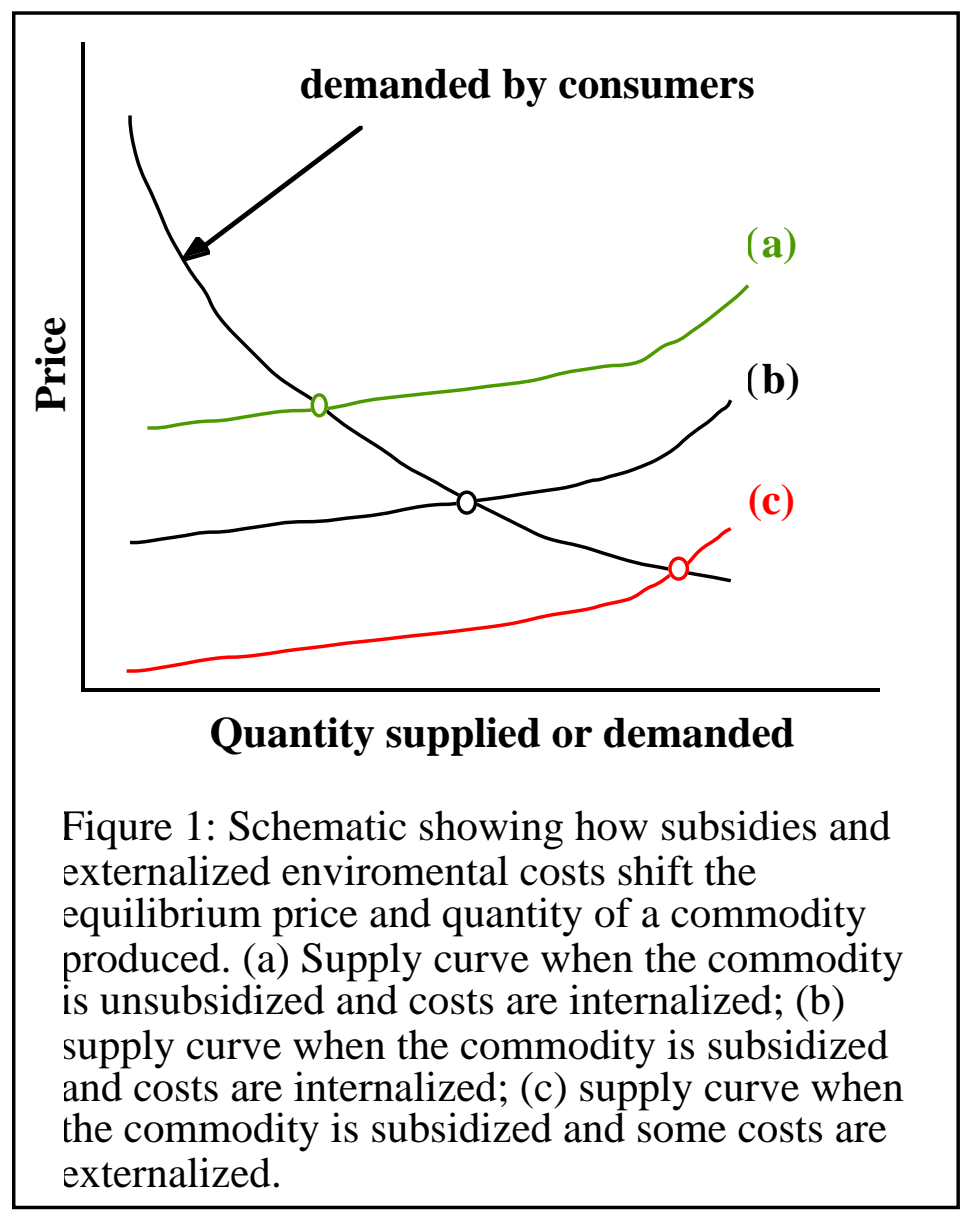


When a commodity is subsidized, its price decreases (other things being equal), which lowers the supply curve (Fig. 1: curve moves from (a) to (b)). If some of the costs of producing or consuming a commodity are not included in its price, then this lowers the supply curve still further (Fig. 1(c)). Because many countries subsidize fossil fuel production and because environmental costs are externalized, the fossil fuel supply curve currently corresponds to Fig. 1(c). Shifting to curve (a) would increase the price of fossil fuels, decreasing the amount produced and consumed, and help avert the tragedy of the commons.

As would be the case for any further restriction on the use of the global commons, there is opposition to ending subsidies and externalization of environmental costs. But there are recent examples of governments moving in this direction. Roodman [3] lists twelve nations that have reduced fossil fuel subsidies by $17-100 \%$ in the past fifteen years. Several European countries have also successfully taxed pollution and resource depletion to reflect the true environmental costs [3]. Of course, tax increases are unpopular. To avoid tax increases, seven European nations recently shifted taxes from personal income or wages, to environmentally destructive industries. This makes particularly good sense: why tax activities that societies generally want, while subsidizing those we don't want [3]? That mainstream support exists for government price regulation in order to avert tragedies of the commons is suggested by recent commentary in The Economist [12]. A pair of articles, one entitled "The tragedy of the oceans," argued that the collapse of marine fisheries (a classic commons problem) has been driven by government subsidies, and argues that government pricing in the fisheries industry is required.

None of the arguments reviewed here is especially novel. But we believe that they provide an essential context for discussions of energy prices and funding for alternative energy research. Of course, it could be that when coming from those involved in fusion research, these arguments will only be perceived as special pleading. Our position is the opposite: consumers and producers are unlikely to argue for the changes necessary to prevent a tragedy of the commons. If scientists won't, who will?

\footnotetext{
${ }^{\mathrm{a}}$ RBudny@ @rinceton.edu; work supported in part by the US DoE Contract No. DE-ACO2CHO3073.

${ }^{\mathrm{b}}$ RWinfree@princeton.edu
} 


\section{REFERENCES}

1 Flavin, C. and Dunn, S. (1999) Reinventing the energy system in State of the World 1999 , pp. 22-40. (Brown, L., Flavin, C. and French, H., eds.). New York: The Worldwatch Institute and W. W. Norton

2 Najmabadi, F. and the ARIES Team. (1997) Overview of the ARIES-RS reversed-shear tokamak power plant study, Fusion Engineering and Design 38, pp. 3-25. Elsevier Science

3 Roodman, D.M. (1999) Building a sustainable society, pp. 169-188 in State of the World 1999 (Brown, L., Flavin, C. and French, H., eds), New York: The Worldwatch Institute and W. W. Norton

4 Hardin, G. (1968) The tragedy of the commons, Science 162, pp. 1243-1248

5 Gordon, H. S. (1954) The economic theory of common property resources, Journal of Political Economy 62, pp. 124-142

6 Dasgupta, P. (1993) An Inquiry into Well-being and Destitution, pp. 161-164. Oxford, Claredon Press

7 Ridley, M. and Low, B.S. (1993) Can selfishness save the environment?, Atlantic Monthly September, pp. 76-85

8 Kay, C.E. (1997) The ultimate tragedy of the commons, Conservation Biology 11, pp. 1447-1448

9 Pigou, A.C. (1946) The Economics of Welfare, $4^{\text {th }}$ ed. London: MacMillan

10 Lipsey, R.G. et al. (1993) Economics, $10^{\text {th }}$ ed. New York: Harper Collins

11 Nicholson, W. (1998) Microeconomic Theory: Basic Principles and Extensions, $7^{\text {th }}$ ed. Fort Worth: Harcourt, Brace

12 Anonymous. (1994) The tragedy of the oceans and The catch about fish, The Economist, March 19, pp. 21-24 and 13-14 